\title{
The Learning of Complex Speech Act Behaviour
}

Elite Olshtain

Andrew Cohen

\begin{abstract}
The study reported in this article concerns itself with the learning and teaching of the more subtle and complex features of the speech act of apology in English. Based on the knowledge that we have to date on apology speech act behaviour, we addressed ourselves to questions relating to the efficacy of teaching such elements as: choice of semantic formula; appropriate length of realization patterns; use of intensifiers; judgment of appropriacy and students' preferences for certain teaching techniques. In order to attempt and answer these questions we carried out a training study with 18 adult learners of English, speakers of Hebrew. The study consisted of : a) a pre-teaching questionnaire aimed

at assessing the subjects' use of apologies; b) a teaching materials packet covering three classroom sessions and c) a postteaching questionnaire. The findings suggest that although we cannot present clear cut quantitative improvement of the learners' speech act behaviour after the given training programme, we find that there is an obvious qualitative approximation of native like speech act behaviour with respect to types of intensification and downgrading, choice of strategy and awareness of situational factors. We feel, therefore, that the teaching of speech act behaviour is a worthwhile project even if the aim is only to raise the learners' awareness of appropriate speech act behaviour.
\end{abstract}

In recent years, teachers have been encouraged to give attention in their instruction to speech act sets that are likely to be called upon in given speech situations. Such speech act sets have been described for functions such as apologizing, complaining, requesting, complimenting, and the like. It has become increasingly clear to researchers that learners of a language may lack even partial mastery of such speech act sets and that this lack of mastery may cause difficulties or even breakdowns in communication.

Teaching materials dealing with speech acts have for the most part been constructed largely in the absence of empirical studies to draw upon. They have relied on the curriculum writer's intuition and can best be characterized as reflecting a high level of simplicity and generality. Most of the currently popular English-foreign-language textbooks treat speech acts such as "apology" rather simplistically. For example, emphasis is almost exclusively on the expression of an apology: sorry, I'm sorry, I' $m$ very sorry, etc. Brief reference is made to other apology strategies, but without underlying principles for when to use what. No effort is made to analyze 
the apology speech act set into its semantic formulas i.e., the various verbal realizations of an apology (see, for example-Blundell, Higgens, and Middlemass 1982;) Berry and Bailey 1983; Jolly 1984; Swan and Walter 1985).

Studies concerning the nature of apologies in a variety of languages and cultures have been steadily accumulating over the last few years (e.g. Cohen and Olshtain 1981; Olshtain 1983; Olshtain and Cohen 1983; BlumKulka and Olshtain 1984; Cohen, Olshtain and Rosenstein 1986; Olshtain and Cohen 1989; Owen 1983). As a result, there is a growing source of empirical data on the strategies for apologizing. Hence, there is now an opportunity to move from general, intuitively-based materials to more specific, empirically-based ones.

One such textbook series that has two books based on empirical findings from speech act studies is the ESL series developed by Bodman and Lanzano (1981 and 1984). Their coverage of apologies includes reference to the semantic formulas of responsibility and offer of repair, as well as the overt expression of an apology. They also deal with modifications on apologies such as through using comments as softeners. This series was developed before the most recent empirical distinctions, but it definitely takes the learner beyond simplistic coverage of the speech act set.

In the present study we would like to consider the explicit teaching of the speech act of apologizing to advanced EFL learners, based on the empirical findings so far, and to focus on the type of activities that would be most beneficial to such learners. Two rather general research questions have guided our work:

1) Can the fine points of speech act behaviour be taught explicitly in the foreign or second language classroom setting? What techniques are most suitable for such teaching?

2) What level of "speech act proficiency" can be attained? Is a certain level of residual awareness sufficient?

The present paper attempts to search for some answers to these questions with respect to the speech act of apologizing in English as taught to a group of advanced adult Hebrew speakers in a foreign language context.

\section{What Do We Know About The Speech Act Of Apologizing?}

\section{The Apology Speech Act Set}

An apology is a speech act which aims to provide support for the hearer (H) who was actually or potentially mal-affected by a violation $(\mathrm{X})$ for which the speaker (S) is at least partially responsible. When apologizing, the $S$ is willing to humiliate him/herself to some extent and to admit to fault and responsibility for $\mathrm{X}$. Hence, the act of apologizing is face-saving 
for the $\mathrm{H}$ and face-threatening for the $\mathrm{S}$, in Brown and Levinson's (1978) terms. According to Leech's (1983) "tact maxim", apology is a convivial speech act whose goal coincides with the social goal of maintaining harmony between $S$ and $H$. Leech's terms, therefore, the realization of an apology provides benefit for the $\mathrm{H}$ and is to some degree at cost for the $\mathrm{S}$.

The five strategies (semantic formulas) which make up the speech act set of apology (Olshtain and Cohen 1983) consist of two which are general and do not depend on contextual constraints, and three which are situation specific. The two general strategies are: the explicit expression of an apology which contains the formulaic, routinized apology expressions $\left(I^{\prime} m\right.$ sorry, excuse me, I regret . . . etc.) and the expression of responsibility which reflects the S's degree of willingness to admit to fault for X. Potentially, the expression of an apology and/or the expression of S's responsibility could realize an apology act in any situation. The first contains the explicit, performative verbs which express an apology in each language. The second, the expression of responsibility in Goffman's terms, as cited by Owen (1983), contains substrategies which relate to "pleas for excusable lack of foresight and pleas for reduced competence and admissions of carelessness". These two strategies which are inherently related to the S's willingness to express an apology for a violation can be used across all situations which require the act of apology. The other three strategies, the explanation, the offer of repair and the promise of forebearance are situation specific and will semantically reflect the content of the situation.

In addition to the main strategies which make up the speech act set, there are ways in which the speaker can modify the apology by either intensifying it or by downgrading it. An intensification would make the apology stronger, creating even more support for $\mathrm{H}$ and more humiliation for $S$. The routinized intensification usually occurs internally to the apology expression (internal modification) in the form of a conventional intensifier such as very, really, terribly, deeply and others. External modification can take the form of a comment with added concern for the $\mathrm{H}$ which intensifies the apology since it expresses stronger interest on the part of $S$ to placate $\mathrm{H}$. External modification which downgrades the apology, lessening its strength or sincerity, can take the form of a comment which minimizes either the offence or the harm it may have caused. Thus a "downgraded" apology may sound less sincere and may not be accepted as an apology.

\section{Cross-linguistic Apology Behaviour}

In a study comparing strategy preferences in a number of different languages across seven apology situations (Olshtain, in press), the findings indicate surprising similarity. Table One presents the use of the speech act 
set in three different languages (Hebrew, Canadian French and Australian English). What becomes immediately obvious is the common tendency to use the two general strategies in all seven situations at a usage range of $60 \%$ to $75 \%$ across the three languages. The other strategies are situation dependent and much more limited in usage.

\section{Table 1}

Percentages of Strategy Selection from Total Number of Possibilities

Three Languages Across Seven Situations*

(Response in Percentages)

Exp. of

Language apology Respon. Explan. Repair Forb. Intensif. Minim. Concern

Hebrew
$\mathrm{N}=1211 \quad 63 \% \quad 66 \% \quad 5 \% \quad 18 \% \quad-\quad 21 \% \quad 14 \% \quad 8 \%$

Canadian

French

$\mathrm{N}=882$

66

68

10

13

$11 \quad 15$

2

Australian

English

75

71

4

12

24

5

* Tables One, Two and Three are taken from Olshtain (in press)

Tables Two and Three compare the usage of the two main strategiesthe expression of an apology and the expression of responsibility in four languages (Hebrew, Canadian French, Australian English and German) across the seven situations. From close observation of the data presented in Table Two, it seems quite obvious that the average rank order of use of an expression of apology in the seven given situations is fairly consistent across the four languages, and this conclusion is further supported by the average Spearman rank order correlation ( $r s a v=.70$ ).

Amazing similarity in the choice of the expression of responsibility was exhibited in the four languages in all seven situations as can be seen from Table Three. The average Spearman rank order correlation of these data was as high as .92. It is interesting to note an extremely low preference for this strategy in all languages in the situation where a waiter brings the wrong order; in none of the languages is there a tendency to provide explicit responsibility because this may cause the waiter to lose his job. 


\section{Table 2}

A Comparison of the Use of Explicit Apology Strategies in Four Languages (Response in Percentages)

\begin{tabular}{llccc} 
Situation & Hebrew & C. French & Austr. English & German \\
& $\mathrm{N}=173$ & $\mathrm{~N}=126$ & $\mathrm{~N}=218$ & $\mathrm{~N}=200$ \\
\hline 2 professor & $38 \%$ & $43 \%$ & $45 \%$ & $79 \%$ \\
4 student & 77 & 71 & 82 & 81 \\
6 manager & 81 & 92 & 89 & 84 \\
8 waiter & 70 & 84 & 76 & 84 \\
10 late & 57 & 63 & 72 & 67 \\
12 driver & 76 & 61 & 87 & 52 \\
14 insult & 41 & 51 & 61 & 37 \\
\hline
\end{tabular}

$\operatorname{rsav}=.70$

(Spearman rank order correlation)

Table 3

The Distribution of the Strategy of Responsibility

Response Percentage in Four Languages

\begin{tabular}{lcccc} 
Situation & $\begin{array}{c}\text { Hebrew } \\
\mathrm{N}=173\end{array}$ & $\begin{array}{c}\mathrm{C} . \text { French } \\
\mathrm{N}=126\end{array}$ & $\begin{array}{c}\text { Austr. English } \\
\mathrm{N}=218\end{array}$ & $\begin{array}{c}\text { German } \\
\mathrm{N}=200\end{array}$ \\
\hline 2 professor & $83 \%$ & $94 \%$ & $83 \%$ & $94 \%$ \\
4 student & 96 & 96 & 95 & 96 \\
6 manager & 82 & 87 & 95 & 85 \\
8 waiter & 14 & 36 & 16 & 30 \\
10 late & 54 & 51 & 66 & 65 \\
12 driver & 54 & 57 & 69 & 77 \\
14 insult & 63 & 56 & 70 & 76 \\
\hline
\end{tabular}

rsav $=.92$ 
The results of the study quoted here raise an important question with respect to teaching the speech act of apology. If languages show such high levels of agreement in strategy selection as we have seen here, is it really necessary to teach strategy selection? It is most likely that at least the choices of the two general strategies in apology usage will be quite similar in all languages and advanced students will have no difficulty in this area. Perhaps the beginners in second language acquisition will need to familiarize themselves with the best equivalents in the target language to the explicit apology forms of their own language since straightforward translations do not usually work too well. But this type of knowledge can be acquired at the early stages of the course. Our study focusses on what needs to be taught at the advanced level.

\section{What Remains to be Learned at the Advanced Stage?}

Cohen, Olshtain, and Rosenstein (1986) studied Hebrew speaking advanced learners of English focussing on strategy selection and use of modifications of the main strategies. The learners' speech act behaviour was compared to that of native speakers of English living in the US. The findings showed that there were not many differences between the natives and the non-natives with regard to the utilization of the five strategies for apologizing included in the speech act set, which could be expected given the non-natives' advanced level of English proficiency. Especially similar was non-native and native behaviour with respect to the selection of the two main strategies-the explicit expression of the apology and the expression of responsibility.

The differences, to the extent that they existed, were in the use of realization choices within the main strategies. Thus, non-natives used mostly sorry as the realization of the explicit apology even in situations where native speakers also tended to use excuse me. The most striking differences, however, emerged in the various types of apology modifications. The non-natives were found to intensify their expression of apology significantly more than the native speakers and they used a greater variety of intensifying forms than did the native speakers (e.g. terribly, awfully, truly). This finding suggested that the non-natives were less discriminating as to which form of intensification would be appropriate in a given situation.

As a case in point, the non-natives did not use really in the way that the natives did. They attributed to the intensifier very the same semantic properties as to really, while the natives tended to make a distinction-i.e., such that really expressed a greater depth of apology and concern. For example, in a situation where a friend scalded another one with coffee in the cafeteria, natives tended to use really sorry while non-natives used 
very sorry which sounded less intensified. The overuse of very as an intensifier among learners may of course derive directly from the teaching materials which present this form as the most useful or sometimes the only intensifier of an apology.

In most situations used in the study, the natives used emotionals more frequently than did the non-natives, this difference being statistically significant in six different situations. Emotionals are expressions such as $O h$, $m y$ ! or similar interjections, attached to the apology realization and have been found to be common intensifiers in all languages investigated. In fact, it is these additional interjections that make the apology sound sincere and meaningful. Non-natives tend to avoid emotionals since they seem to have difficulty in developing the proper sensitivity to use them. As a result, non-native apologies might sound formulaic rather than genuine.

The findings of the studies described above served as the basis for the hypotheses of our present study.

\section{The Study}

The two general research questions presented at the beginning of this paper were translated into five more specific and operational questions which were tackled in the present study. They are:

1) Do the number and type of semantic formulas used by the students change as a result of instruction?

2) What is the average length of responses (apology speech act realization patterns) before and after instruction?

3) What is the frequency of use and the nature of intensifiers before and after instruction?

4) How do students' and native speakers' judgments of appropriacy compare?

5) How do students evaluate teaching materials which deal with explicit instruction in speech act behaviour?

In order to answer these questions two types of instrumentation were developed: a) pre- and post-teaching questionnaires aimed at tapping the students knowledge of apology speech act behaviour in English and b) materials for the teaching of specific features of apology which had been found to be problematic for non-native speakers.

Data were first collected from native speakers in order to set up the native norms for the situations utilized in this study. The non-native speakers, students in three different advanced English courses, were then given the pre-questionnaires and on the basis of the deviances from native norms that were encountered, materials for three classroom sessions were developed and administered during the regular course of study. One week 
after the third and final teaching session, the students received the postquestionnaires in order to assess changes in their speech act behaviour.

\section{Subjects}

The study was carried out with 18 adult learners of English, native speakers of Hebrew, 10 studying in private language schools and 8 in a teachers' college. Eleven native speakers of American English, living in Israel (for less than two years), made up the native group which filled out the same questionnaires and thus provided norms concerning speech act behaviour in the given situations.

\section{Instrumentation}

1) A pre-teaching questionnaire consisting of a total of 18 items, including 11 discourse completion items and 7 appropriacy items, was adapted for this study from questionnaires developed by Cohen, Olshtain and Rosenstein (1986). The pre-teaching questionnaire had situational items covering three speech acts: 7 apologies, 6 requests, and 5 complaints. The questions on requests and complaints were used to reduce the focus on the apology items (Appendix A).

2) Teaching materials covering three classroom sessions of 20 minutes each were developed on the basis of deviance found in the answers to (1) above in comparison to native speakers' responses. These materials consisted of six different elements: a) the teachers' explicit explanation of speech act behaviour in English apology realizations; b) information sheets presenting the main points of the lesson; c) role-play activities with specification pertaining to the apology situation and the relations holding between participants; d) pair work activities in which students were expected to discuss appropriacy of apology realizations in given situations; e) listening to native-speaker dialogues involving the use of apologies; f) classroom discussion of the ways in which apologies are realized in English (a detailed description of the three sessions is given below).

3) A post-teaching questionnaire consisting of 9 discourse completion items was given after the three teaching sessions and was based on the pre-questionnaire including the original 7 apology items and two additional ones. The questionnaire also included 5 questions asking students to evaulate the lessons and materials used for the teaching of apologies in their course (Appendix B).

\section{The Three Teaching Sessions}

Lesson 1. The first lesson was devoted to the teaching of the difference between the uses of the two possible realizations of the expression of 
apology-excuse me and I'm sorry-since research had indicated that nonnative speakers did not know how to use these two forms appropriately. In the pre-questionnaire non-natives used excuse me less often than native speakers. The lesson was structured in the following sequences of activities:

1. Presentation of two model dialogues containing examples of the two forms.

2. Discussion of the difference in use of the two forms as demonstrated by the dialogues.

3. A description of the distinctions between the two forms by means of an information sheet.

4. Communicative use of the two forms by students practising role-play in pairs.

5. Student feedback on the lesson and discussion of the various activities.

Lesson 2. The second lesson was devoted to raising the students' awareness of the importance of situational and social factors in the speakers' choice of the particular apology strategy and in the choice of intensifiers and emotionals. From the pre-questionnaire data it became obvious that although learners used similar strategies in the given situations to those employed by native speakers, they intensified their act less and they minimized using emotionals. The objective was to make learners aware of the need to intensify the apology when speaking to a person of a higher social status or in a case where the offence was severe. They were also made aware of the fact that in colloquial speech emotionals can intensify the apology and give it a more sincere quality. The lesson was structured in the following sequence:

1. Presentation of an intensification scale for English apologies.

2. Examples illustrating that scale.

3. A communicative activity which required students to role-play given situations, paying special attention to the relationship between the interlocutors and to the severity of the offence. The activity was carried out in groups of three; two students participated in the role-play and the third student observed the interaction and evaluated the appropriacy of strategy choice.

4. Feedback and discussion.

Lesson 3. The third lesson dealt with varied situations requiring the realizations of all five semantic apology formulas of the speech act set. Here again the focus was on contextual information. The lesson was structured in the following sequence:

1. An oral presentation of semantic formulas and modifiers.

2. A description of the various strategies by means of an information sheet. 
3. A listening comprehension exercise involving a dialogue including all the apology strategies.

4. A second listening to the dialogue, followed by a discussion among the students focusing on the different formulas and on the possible reasons why the interlocutors in the dialogue chose them. Focus on the appropriacy of strategy choice.

5. Feedback and discussion of the activity.

6. Review and discussion of the entire teaching unit on apologies.

\section{Findings}

In our discussion of the findings we will first return to the six specific and operational research questions and in our conclusion we will attempt to summarize the implications relating to the two general research questions underlying this study.

The first question related to the number and type of semantic formulas utilized in the apology realization. The most significant difference between native speakers and the advanced learners participating in the study, as exhibited by answers on the pre-teaching questionnaire, was the fact that often non-native speakers used only one strategy other than the explicit apology, while native speakers tended to add to that strategy an explicit apology. When comparing the actual number of strategies used in pre- and post-questionnaire the difference is not obvious but a qualitative analysis yields interesting changes in students' choice of apology realizations. The following are some examples:

Student A-in a situation where s/he forgot to buy medicine for the sick child of a neighbour:

pre: Unfortunately not yet, but I'll be happy to do it right now

post: I'm deeply sorry. I can do it right now.

In this case the number of strategies used to apologize has not changed but the actual choice is different. While in the pre-situation the student used a weak expression of responsibility (I have unfortunately not yet bought it.) and an offer of repair, in the post-situation the same student presented an intensified expression of apology and an offer of repair. The post version was more acceptable to native speakers in this situation.

Student $\mathrm{B}-$-in a situation where $\mathrm{s} / \mathrm{he}$ arranged to meet a friend in order to give her some class notes and $s /$ he showed up half an hour later. The friend calls up on the phone to complain about waiting for over half an hour.

pre: Are you sure? I came only 15 minutes later and you were gone post: Terribly sorry. I completely forgot about it. 
In this case the student actually rejected the need to apologize in the pre-teaching situation and went as far as blaming the $\mathrm{H}$. On the post-questionnaire, the same student offered two strategies-an explicit and intensified expression of an apology and an expression of responsibility. Thus, although quantitatively the difference between pre- and post-data were not significant, the qualitative difference indicated a definite accommodation towards native-speaker behaviour.

The second question focuses on utterance length which characterized the native behaviour as compared to the non-native realizations. The findings indicated that students exhibited longer utterances in their pre-data in comparison to native speakers. This is typical of an advanced-intermediate stage of language acquisition where learners are uncertain about their ability to communicate their real intentions and so they tend to use "too many words." This confirms the findings presented by Blum-Kulka and Olshtain (1985) where the authors suggest that utterance length can function as a potential and unintended violation of a native norm which might lead to pragmatic failure. In the post-data of our present study, there were signs that students had become more confident in the use of appropriate apology strategies and their utterances had become shorter and more matched to the native norm. Examples:

Pre-teaching:

A: Did you wait for me? You must forgive me, I could not come because of problems and I tried to warn you by phone but . . .

B: Sorry, I missed the bus, the bus was late and I came late but you were not there.

Post-teaching:

A: Terribly sorry madam. Let me give you a hand.

B: Oh, I'm so sorry. It dropped out of my mind.

The third research question related to the use of intensifiers. In the teaching unit on apologies, learners were encouraged to use intensifiers in their expressions of apologies as this was one of the important differences between native and non-native speech. This was probably the one area were the teaching unit was most successful and at least in two apology situations there was a significant increase in the use of intensifiers:

A meeting with a friend which was missed: while on the pre-teaching questionnaire $40 \%$ of the students' utterances contained intensifiers, on the post-questionnaire $60 \%$ of the utterances reflected intensification.

Forgetting to buy medicine for a neighbour: only $20 \%$ of the utterance on the pre-questionnaire contained intensifiers and a full $90 \%$ of the utterances in the post-questionnaire did so. 
The fourth research question related to students' judgments of the appropriacy of the apology realization. With regard to the set of alternative responses for each of the three items, one of the alternatives preferred by natives (e.g., above $75 \%$ preference) was also preferred more by nonnatives after the training period: in the situation of forgetting to return a book to the professor, the alternative preferred by the native speakers was (d) Oh, I'm very sorry, I completely forgot. In post-testing, non-native speakers selected this option more than they had in pre-testing. However, the overall variation among non-natives was still quite different from that of the natives. This finding is consistent with Olshtain and Blum-Kulka (1985) that it takes 8 to 10 years in the target language community in order to acquire native-like variation.

The fifth research question related to the students' evaluation of the teaching materials. After each session on apologies they were asked to circle one or more activity that they found particularly useful during that lesson (teacher's explanation, information sheets on apologies, role-play activities, pair work, listening to apology dialogues and classroom discussion). This accumulated evaluation of the teaching units resulted in the following average preferences by activity types:

1. Teacher's explanation $60 \%$

2. Information sheets $40 \%$

3. Role-play activities $\quad 40 \%$

4. Pair work (matching) $20 \%$

5. Listening to dialogues $20 \%$

6. Classroom discussion $20 \%$

It is interesting to note that most students attached the highest value to the teacher's explanation of how to use the apology. Such high preference for formal presentation of the topic as exhibited by the students participating in this study (teacher's explanation, information sheets) can possibly be attributed to the fact that these were adult learners who may have felt more comfortable with the explicit presentation of a new topic than with experiential types of activities. This reaction might be different with different populations.

In addition to the written rankings of the activities, students also provided oral feedback. A notable element that emerged from this feedback was the fact that most of the students participating in this study had only been vaguely aware of speech acts in general and apologies in particular prior to instruction. Our findings would suggest that such awareness in and of itself can play a beneficial role in improving non-native speech act behaviour. 


\section{Conclusion}

The students in our case had reached an overall advanced level of English before they participated in this study. Yet, the pre-teaching questionnaire indicated that they were not always choosing the most appropriate apology strategy and that they were often not providing the expected intensification of the strategies chosen. As a result of such deviation from the native norm these learners of English might have experienced pragmatic failure when interacting with native speakers since their apologies, although they were made in the appropriate context might have sounded insincere or weak because they were lacking the proper intensification. Thus, if somebody you know bumps into you, hurting you and only says Sorry this would be considered an insincere apology or even no apology. The native speaker in this case would expect the intensification via a terribly sorry or some emotional such as $O h, m y, I ' m$ really sorry. As a result of the teaching sessions our students have learned to make such intensification and most importantly to be aware of when such upgrading of the apology strategy seems appropriate. This would make them more successful communicators in English as a second language.

Even so, it is hard to draw definitive conclusions on the basis of the study presented here as to the overall efficacy of a teaching programme in speech acts. However, we feel that we can answer the two general research questions underlying this study. With respect to the first question, qualitative analysis of the data collected in this study would suggest that the fine points of speech act behaviour such as (1) types of intensification and downgrading, (2) subtle differences between strategy realizations, and (3) consideration of situational features, can and should be taught in the second and foreign language classrooms. We have demonstrated a variety of teaching techniques that can be employed for this purpose, and obviously more types can be developed as we gain better insight into the acquisition of speech acts.

We are much more skeptical, however, with respect to the second question dealing with the proficiency level of speech act behaviour. ESL or EFL learners need to acquire not only a new repertoire of realization patterns in the new language but also change some of their speech act behaviour. Such change in behaviour may take a long time. As was pointed out by Olshtain and Blum-Kulka (1985), “. . . only after many years of stay within the target speech community do learners begin to react like native speakers would." It is therefore a level of residual awareness that we wish to promote as the objective of any explicit course of study. We believe that once such awareness is established, the learners will be less prone to commit pragmatic failure both as producers and receivers of speech act behaviour, and that this awareness might ultimately speed up their approximation of native behaviour. 


\section{ACKNOWLEDGMENTS}

We would like to thank the Aran Foundation for Educational Research for the financial support for this study.

We would like to thank the MA-TESOL students at Tel Aviv University: Hannah Peretz, Orly Bambagy, Judy Steiner and Yonit Bornstein for their help with the data collection and analysis.

\section{REFERENCES}

Berry, C. and D. Bailey. (1983). Video English. London: MacMillan.

Blum-Kulka, S. and E. Olshtain. (1984). Requests and apologies: A cross cultural study of speech act realization patterns (CCSARP). Applied Linguistics 5, 196213.

Blum-Kulka, S. and E. Olshtain. (1986). Too many words: Length of utterance and pragmatic failure. Studies in Second Language Acquisition 8 (2), 165-179.

Blundell, J., J. Higgens, and N. Middlemass. (1982). Function in English Oxford: Oxford University Press.

Bodman, J. W., and M. K. Lanzano. Milk and Honey: an ESL series for adults. NJ: HBJ Center for Lifelong Education. (Books 2 and 4 use the functional approach, with apologies covered in Book 4, pp. 40-51).

Cohen, A. D. and E. Olshtain. (1981). Developing a measure of sociocultural competence: The case of apology. Language Learning 31, 113-134.

Cohen, A. D. and E. Olshtain. (1985). Comparing apologies across languages. In K. R. Jankovsky (Ed), Scientific and Humanistic Dimensions of Language. Amsterdam: John Benjamins, 1975-184.

Cohen, A. D., E. Olshtain, and D. Rosenstein. (1986). Advanced EFL apologies: What remains to be learned. International Journal of the Sociology of Language $62(6), 51-74$.

Jolly, D. (1984). Writing Tasks. Cambridge: Cambridge University Press.

Olshtain, E. (1983). Sociocultural competence and language transfer: The Case of Apology. In S. Gass and L. Selinker (Eds.) Language Transfer in Language Learning Rowley, MA: Newbury House, 232-249.

Olshtain, E. (in press). Apologies across languages. In Blum-Kulka, S., J. House, and G. Kasper (Eds.) Cross-cultural Pragmatics: Requests and Apologies. Norwood, N.J.: Ablex, 155-174.

Olshtain, E. and S. Blum-Kulka. (1984). Cross-linguistic speech act studies: Theoretical and empirical issues. In L. MacMathuna and D. Singleton (Eds.) Language Across Cultures. Dublin: Irish Association for Applied Linguistics, 234-248.

Olshtain, E. and S. Blum-Kulka. (1985). Degree of approximation: non-native 
reactions to native speech act behaviour. In S. Gass and C. G. Madden (Eds.) Input in Second Language Acquisition. Rowley, MA: Newbury House, 303325.

Olshtain, E. and A. D. Cohen. (1983). Apology: A speech act set. In N. Wolfson and E. Judd (Eds.) Sociolinguistics and Language Acquisition. Rowley, MA: Newbury House, 18-35.

Olshtain, E. and A. D. Cohen. (1989). Speech act behaviour across languages. In H. W. Dechert et al (Eds.) Transfer in Production. Norwood, N.J.: Ablex, 53-68.

Owen, M. (1983). Apologies and Remedial Interchanges. Amsterdam: Mouton.

Swan, M. and E. Walter. (1985). Cambridge English Course. Book 2. Cambridge: Cambridge University Press.

\section{APPENDIX A}

LANGUAGE USE QUESTIONNAIRE (PRE-QUESTIONNAIRE)

Background Information

Name

Age Sex M/F Mother Tongue

If non-native English speaker, rate your speaking ability:

Excellent Good Fair Poor

Time spent in English-speaking community, if any: years, months

Previous use of English with native speakers:

Frequent Occasional Rare

Current use of English with native speakers:

Frequent Occasional Rare

\section{PART I-INSTRUCTIONS:}

Please put yourself in the following situations and assume that in each instance the speaker will, in fact, say something. Write down what you think would be said (in English), in the space provided. Make sure that you read the whole situation carefully before you respond.

1) Ann missed a class the day before and would like to borrow Judith's notes.

Ann:

2) You are running to catch a bus. You unintentionally bump into an older woman causing her to drop some packages.

You:

3) You forgot to call a close friend on her birthday. The next day you go to visit her.

You:

4) Your car has been in the garage for repairs for the past two weeks. You are 
a regular customer at the garage and the owner had promised you that the car would be ready today. In the afternoon the owner informs you that the car won't be ready after all, even though he knows that you need it urgently that evening.

You:

5) This is not the first time that your neighbor has played loud music late at night, and you have to get up early the next morning. You phone him:

6) A friend arranged to meet you in order to get some notes from you to study for an exam. S/ he waited for an hour but you didn't show up. S/ he calls you up

Friend: You know, I waited for you for an hour yesterday.

You:

7) The meeting has just ended. Bob's bus has just left and the next one will not be along for another hour. The couple sitting next to him live on the same street and have come by car. He'd like a ride with them:

Bob:

8) You promised you'd buy your neighbor medicine for her sick child while in town, but you forgot.

Neighbour: Were you able to get the medicine?

You:

9) A friend who studies with you at the university refuses to share important notes $s /$ he has managed to get hold of before the final exam. You are quite upset because you've often helped him/her in the past.

You:

10) A boy is trying to pick up a girl on the street.

Boy: Excuse me, can you tell me what time it is?

Girl: Half past three.

Boy: Are you in a hurry?

Girl: That's none of your business.

Boy: How about having coffee with me?

Girl: No.

Boy: What about tomorrow?

Girl: Listen,

11) You promised to take a friend to a bicyle store to help him choose a new bicycle, but you forgot.

Friend: I waited for you at the bike shop yesterday, but you never came.

You:

\section{PART II-INSTRUCTIONS:}

Each of the following questions will provide a description of a situation. Following the situation there are a number of responses. Please evaluate each response separately on a scale from 1 to 3 .

$$
1=\text { acceptable } \quad 2=\text { more or less acceptable } \quad 3=\text { not acceptable }
$$

1) Ruth, a friend of yours at the university, comes up to you after class and tells you that she has finally found an apartment, but that she must pay $\$ 300.00$ 
down payment immediately. At present she only has $\$ 200.00$. She turns to you and says:
a. How about lending me some money?
b. So do me a favor and lend me some money.
c. I'd appreciate it if you could lend me the money.
d. Could you possibly lend me the money?
e. Do you think you could lend me the money?
f. I promise I'll pay you back right away.
g. Lend me the money, please.

2) You have just finished cleaning the house when your children walk in with dirt and mud all over their shoes. You say:

a.

b. Haven't I told you a thousand times to take off your dirty shoes before you come in?

c. Why do you have to make a mess all the time?

d. I I can't believe you. I just got through cleaning in here!

e. I'm fed up! Clean this mess up!

3) A student forgets to return a book to the professor:
a. I'm terribly sorry. I forgot it.
b. _ Oh, damn! I forgot it.
c. Sorry. I forgot.
d. — Oh, I'm very sorry. I completely forgot.
e. I'm really sorry but I forgot to bring it.

4) An applicant for a job has been waiting for quite some time, although s/he had been called in for an appointment for an interview. The manager finally comes out and says:
a. Sorry to have kept you waiting.
b. Sorry I'm late. I hope I didn't keep you waiting too long.
c. Have you been waiting long?
d. I I was unavoidably held up in a meeting.
e. I'm sorry. I was help up.

5) You bought an expensive watch at an exclusive jewelry store. After a few months the watch stops working, so you take it back to the store. They tell you that this is an imported watch which they cannot fix. You say:
a. __ If you can't fix it, then I expect my money back!
b. I would have expected better service from your store.
c. You haven't heard the end of this!
d. I'm really surprised.
e. You'll be sorry about this.
f. _ This is the last time you'll catch me buying anything here!
g. Can't you do anything???
h. I can't believe this.

6) You are at a restaurant with a friend. You want to see the menu in order to decide what you'd like to order. The waiter is nearby, and you turn to him and say:
a. We'd like a menu, please.
b. Could we have a menu, please? 
c. Bring us a menu, please.

d. We need a menu.

e. How about a menu for this table?

f. May we have a menu, please?

7) A young man/woman bumps into you at the supermarket and some of your groceries spill onto the floor. He/she turns to you and says:

a. Sorry.

b.

c. I'm sorry.

d. Terribly sorry.

e. I'm terribly sorry. Did I hurt you?

f. I'm really sorry. Here, let me help you.

f. I'm sorry but you were in my way and I couldn't help bumping into you.

g. Are you all right?

h. Please forgive me.

\section{APPENDIX B}

LANGUAGE USE QUESTIONNAIRE (POST-QUESTIONNAIRE)

\section{Background Information}

Name

Age Sex M/F Mother Tongue

If non-native English speaker, rate your speaking ability:

Excellent Good Fair Poor

Time spent in English-speaking community, if any: years, months

Post high-school education in English, if any: years, months

Current use of English with native speakers:

Frequent Occasional Rare

Participated in $1 / 2 / 3$ of the lessons.

\section{PART I-INSTRUCTIONS:}

Please put yourself in the following situations and assume that in each instance the speaker will, in fact, say something. Write down what you think would be said (in English), in the space provided. Make sure that you read the whole situation carefully before you respond.

1) You are running to catch a bus. You unintentionally bump into an older woman causing her to drop some packages.

You:

2) You forgot to call a close friend on her birthday. The next day you go to visit her.

You: 
3) A friend arranged to meet you in order to get some notes from you to study for an exam. S/he waited for an hour but you didn't show up. $S$ / he calls you up

Friend: You know, I waited for you for an hour yesterday.

You:

4) You promised you'd buy your neighbor medicine for her sick child while in town, but you forgot.

Neighbour: Were you able to get the medicine?

You:

5) You promised to take a friend to a bicycle store to help him choose a new bicycle, but you forgot.

Friend: I waited for you at the bike shop yesterday, but you never came. You:

6) You have to get off the bus at the next stop. You're sitting in the window seat and there is a person sitting next to you.

You want to get off, and say:

\section{PART II-INSTRUCTIONS:}

Each of the following questions will provide a description of a situation. Following the situation there are a number of responses. Please evaluate each response separately on a scale from 1 to 3 .

1-acceptable 2-more or less acceptable 3-not acceptable

1) A student forgets to return a book to the professor:

a. I'm terribly sorry. I forgot it.

b. Oh, damn! I forgot it.

c. L Sorry, I forgot.

d. Oh, I'm very sorry. I completely forgot.

e. I'm really sorry but I forgot to bring it.

2) An applicant for a job has been waiting for quite some time, although s/he had been called in for an appointment for an interview. The manager finally comes out and says:

a. Sorry to have kept you waiting.

b. Sorry I'm late. I hope I didn't keep you waiting too long.

c. Have you been waiting long?

d. I was unavoidably held up in a meeting.

e. I'm sorry. I was held up.

3) A young man/woman bumps into you at the supermarket and some of your groceries spill onto the floor. $\mathrm{He} /$ she turns to you and says:

a. _ـ Sorry.

b. I'm sorry.

c. Terribly sorry.

d. I'm terribly sorry. Did I hurt you?

e. I'm really sorry. Here, let me help you.

f. I_m sorry but you were in my way and I couldn't help bumping into you. 
g. Are you all right?

h. Please forgive me.

\section{PART III-EVALUATION}

1) You've been learning about how to apologize in English. Circle the things that you have found most useful in the classroom. (You can circle as many as you want.)
a Information sheet
b Teacher's explanations
c Pair work
d Role-play
e Writing notes in your notebook
f Listening comprehension
g Class discussion
h Evaluating another group's work
i None of the above

2) Outside of the classroom, did you:

(Circle as many as you want.)
a Try and apologize in English
b Pay special attention to how native speakers apologize in English.
c Re-read the information sheets handed out in class
d Look at your notebook
e Tell your family or friends about the activities you did in class
f Not think about what was done in class

3) When was the last time you apologized in English, outside the classroom?:

4) Look back at questions 1-5. When you wrote down your answers what did you think? (Circle as many as you want.)
a I remembered what I heard in class
b I heard it once somewhere
c I remembered what I wrote in my notebook
d I remember the teacher had explained it
e I knew the answer from reading
f I translated it from my mother tongue
g It sounded right
$\mathrm{h}$ Others:

5) Before this project, were you ever taught how to apologize in the classroom? yes no

\section{THE AUTHORS}

Elite Olshtain is Professor of Language Teaching at Tel Aviv University at the School of Education and the Department of Linguistics. Her research interests are in: discourse analysis, language attrition, factors affecting success in language acquisition, curriculum development. She has published articles in various professional journals and anthologies and is co-author (with Fraida Dubin) of Facilitating 
Language Learning (McGraw Hill, 1977), Reading by All Means (Addison-Wesley, 1981 and 1989), Reading on Purpose (Addison-Wesley, 1986) and Course Design (Cambridge University Press, 1986).

Andrew D. Cohen is Professor of Language Education, School of Education, Hebrew University of Jerusalem. He has written numerous research articles on language teaching and learning, and books on bilingual education, language testing, and most recently on language learning strategies (Language Learning: Insights for Learners, Teachers, and Researchers. NY: Newbury House, Harper Row, in press). 